\title{
El EsPacio Público EN CaRTagena de INDIAS, RESISTENCIAS COTIDIANAS
}

\author{
Por: Carmen Cabrales Vargas \\ Marcelo Cáceres Cabrales
}

\section{Acercándonos a la Ciudad}

\rceil l terreno de la confrontación por el espacio público en Cartagena es - un fenómeno que se volvió visible en la ciudad, por lo menos para los I_ observadores atentos, pero no así para las autoridades encargadas de regular los usos y actividades del mismo ni para el grueso de la población que la habita.

Su imagen de ciudad puerto ha generado imaginarios que la han convertido en una ciudad de oportunidades que la mantiene recibiendo población venida de Departamentos de la Costa Caribe colombiana y del interior país. Sumado a esto, su acelerado crecimiento poblacional en las tres últimas décadas, la débil voluntad política en la aplicación responsable de los planes de desarrollo, su movilidad geográfica y social, poco estudiada y débilmente encauzada, la mantienen en una crítica situación en la que sobresale la extrema desigualdad social; las escasas oportunidades de empleo, y la falta de compromiso y responsabilidad de sus autoridad y habitantes para con ella.

A pesar de la declaratoria de Cartagena como Patrimonio Histórico de la Humanidad, ésta no se ha constituido lo suficiente como patrimonio material e inmaterial y sus habitantes no han incorporado esta realidad en su relación con la ciudad. Sin reglas concertadas que guíen las actuaciones de sus habitantes, la ciudad no tiene un orden ni un norte que asegure una convivencia constructiva entre habitantes y espacios públicos; de otra parte no nos hemos dado a la tarea de formular reglas surgidas en la confrontación de discensos en torno a las prácticas de ocupación de los espacios públicos por parte de los diferentes sectores sociales que la habitan.

Una lectura cuidadosa de la ciudad permitirá comprobar que es diversa étnica, cultural y socialmente, que no se le puede tratar como un espacio urbano sencillo 
y homogéneo. Por el contrario es en alguna medida cierta la afirmación, de aparente sentido común, acerca de la existencia de dos o tres Cartagena; por lo pronto solo queremos sugerir la coexistencia de una serie de situaciones que la convierten en una ciudad altamente amalgamada donde en sus espacios se mezcla la ciudad turística, la ciudad apropiada por los ricos locales, nacionales, e internacionales, la ciudad sitiada por los pobres que ya entraron a la zona histórica destinada al turismo y no a los habitantes locales, la ciudad de la gente común.

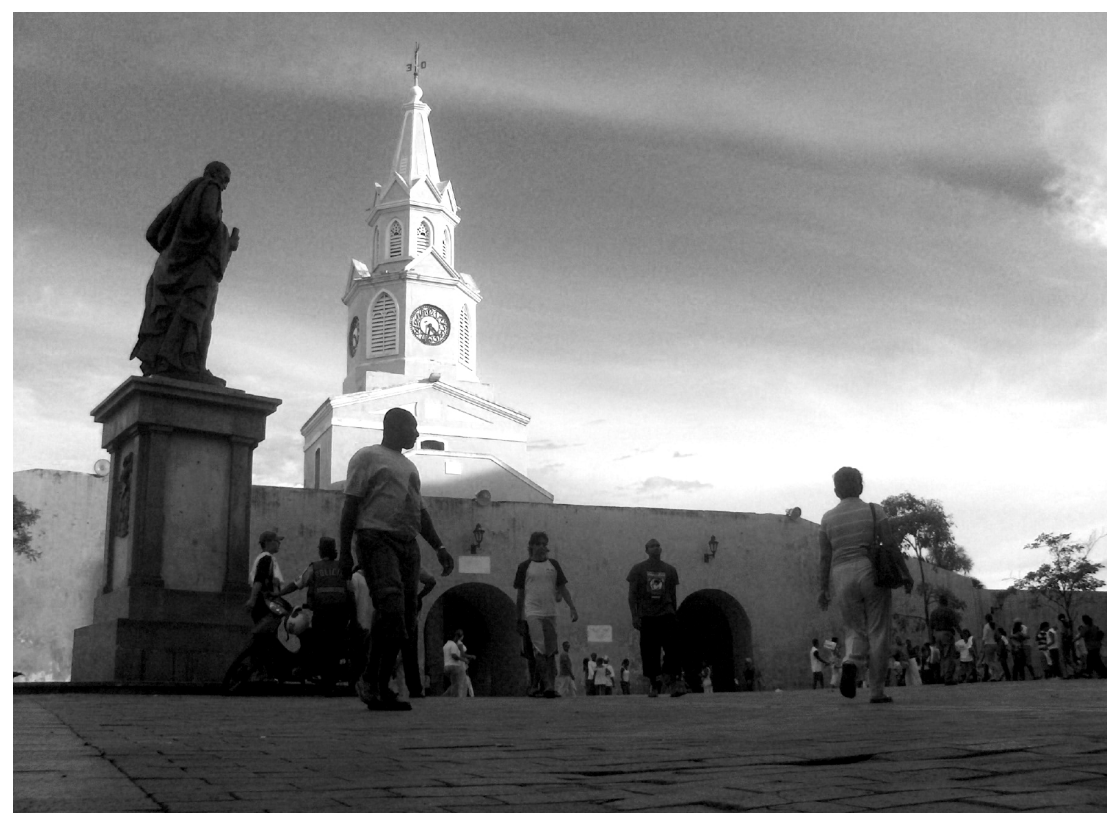

Foto: Juan López Rodríguez, Universidad de Cartagena.
Walter López Borbón con referencia a la dinámica de espacios públicos en ciudades colombianas anota que "...el espacio público, tanto en los asentamientos populares como en las áreas comerciales e institucionales, ha sido el tradicional escenario de importantes grupos de vendedores, promotores, grupos culturales y sociales que le han dado a las calles, plazas y parques otro carácter y sentido, en muchos casos inadecuado e inapropiado. Pero a la vez, han aportado, en la mayoría de los casos, identidad y vocación a amplios sectores de la ciudad, los cuales direccionados y adecuados, pueden llegar a constituirse en piezas claves de la imagen diversa y compleja de la ciudad". ${ }^{1}$

En Cartagena, esta apropiación también sucede y el caos ha tomado el control

${ }^{1}$ López Borbón, Walter. (2004). Cada Cosa en su Lugar y un Lugar para cada Cosa. Reflexiones en Medio de la Recuperación del Espacio Público, En: Pre-til, No 5. Instituto de investigaciones $y$ proyectos especiales, Universidad Piloto de Colombia. pp. 50-53. de casi todos los espacios públicos; por su parte las múltiples manifestaciones sociales en lugar de expresar la convivencia de la multicultural y la complejidad que vive la ciudad, muestra la falta de autoridad y de respeto hacia ella por parte de los habitantes, visibilizando que todavía no hacen su aparición prácticas sociales y usos resultantes de procesos y convocatorias de la sociedad civil, haciendo falta lo que señala Borbón López, un trabajo de direccionar y adecuar los espacios y sus usos para que estos se conviertan en elementos representativos de esa Cartagena multicultural. 


\section{Conflicto por el Uso del Espacio Público en el Centro Histórico. Lo que se Disputa}

El conflicto por la apropiación del espacio público en el Centro Histórico de la ciudad tiene diversas manifestaciones, algunas de ellas se refieren al uso indebido de calles, andenes y plazas por parte del comercio formal y del informal; a la contaminación ambiental, visual y auditiva; al absoluto desconocimiento de las normas de tránsito; al diario aparecer de actividades de rebusque que violan las normas ubicándose en espacios libres propios para el usufructo del peatón.

En esta dinámica en que la ciudad está inmersa, sin saber como ni cuando alcanzó las actuales dimensiones, encontramos que los espacios públicos del Centro Histórico no tienen perfil definido, por lo tanto los habitantes le van dando el que ellos consideren útil de acuerdo a sus necesidades, con ello se ha ido desdibujando el mapa urbano desapareciendo espacios que eran sitios de recreación tales como las plazas, parques, calles o andenes, convirtiéndose de repente y sin regulación aparente en expendios de comida, en parqueo de vehículos, en escaparates de ropa y calzado.

En esta situación no solo intervienen las dinámicas sociales, culturales y políticas que han surgido en la ciudad, sino también la falta de preparación para vivir en ella que acusa a todos los que la apropiamos; ya no sabemos cuales son las funciones básicas de los pasajes, las calles, los andenes, las plazas, los parques, los postes del alumbrado público, las fachadas de los edificios, las paredillas de casas y sitios privados, entre otros. Solo para citar un caso actual, señalemos como los postes del alumbrado público, las paredes de terrenos no construidos se convierten en vallas de publicidad política y allí permanecen hasta cuando el tiempo lo decida.

Es innegable la explosión de formas de apropiar el espacio público que se vienen dando, algunas de ellas tienen más que ver con prácticas rurales que con formas de actuar en el espacio urbano, así lo muestran lo que expenden y el medio utilizado para ello como las carretas llenas de frutas y verduras empujadas por hombres o mujeres que recorren las calles del Centro Histórico. Cartagena, puede pensarse que está ante el fenómeno de ruralización acelerada sin control, lo que se ve a diario es la extensión de actividades productivas propias de los barrios populares y de las plazas de mercado de los pueblos a la ciudad.

De otra parte la ciudad está azotada por el florecimiento de una actividad económica

Palobrano. 8 Agosto/2007 
cuyo crecimiento desmesurado ha desbordado la capacidad de gobernabilidad, este es el caso del medio de transporte conocido como "mototaxismo". Fenómeno que no solo enfrenta a los dueños y conductores de motos, buses y busetas, y a estos con las autoridades, sino que hacen uso indebido de las vías públicas desconociendo las normas de tránsito.

Es innegable la aparición de las resistencias cotidianas y con ellas la formalización del uso de los espacios públicos para actividades que no corresponden a sus usos tradicionales. Hasta el momento no tenemos conocimiento si la ocupación inadecuada del espacio público sea producto de movimientos organizados apoyados por redes no visibles sugiriendo y dirigiendo la toma de dichos espacios, o si solo actúa el modelo de repetición de lo que otros hacen.

\section{Imaginarios Sobre los Usos del Espacio Público}

La impresión que queda al observar los ritmos en los espacios públicos del Centro Histórico de la ciudad es que no estamos interesados en construir espacios donde el adecuado diseño, su amoblamiento, las reglas claras y el cumplimiento de las normas sea un acuerdo entre habitantes, administradores y visitantes, que permita además percibir que es más benéfico crear y mantener dinámicas acordes para los sitios y que éstos cumplan con el propósito para el cual fueron construidos, que cambiar el perfil de los mismos. Esta situación tiene que ver, entre otras, con el hecho que "en la medida en que el habitante no sienta suya la ciudad, no la creará ni recreará; por el contrario, sólo se dará a la tarea de usarla. Pero en esta situación, el único responsable no es el habitante, es también la ciudad que crece, se moderniza y complejiza, olvidando que el eje fundamental en ella es su gente, que es imprescindible construir espacios y apoyar procesos sociales educativos donde todos participen con responsabilidad en su construcción". ${ }^{2}$

En este sentido, entre las cuestiones para reflexionar sobre este aspecto, una sería la de si podrían lograrse acuerdos en la fijación de adecuados límites entre lo público y lo privado, y sobre como podrían lograrse, si en el imaginario colectivo prima la idea que primero están los intereses particulares, la supervivencia y la responsabilidad del Estado en esta cuestión de apropiar el espacio público.

2 Cabrales V., Carmen. (1998). La Educación Ciudadana en la Mira del Plan Estratégico Cartagena Siglo XXI. Nómadas, 9, 142.

Una referencia interesante sobre el tema de los imaginarios que circulan en Cartagena sobre el espacio público está contenida en la tabla 1. Una lectura confrontada de dichos imaginarios con lo que sucede en estos espacios dará una medida aproximada de la claridad que sobre el tema tienen los habitantes de 
la ciudad, como también de la primacía de los intereses particulares sobre los colectivos.

Estas opiniones muestran imaginarios sobre lo que puede y no puede hacerse en los espacios públicos. Parece entonces existir un profundo conflicto entre el significado de los espacios, la función que estos tienen que cumplir, y los usos que por diferentes necesidades le dan; el conflicto por el espacio público hace ya parte de la realidad de esta ciudad y las condiciones que prevalecen en ella harán que permanezca y se agrave si no median procesos constructivos de apropiación.

Tabla 1

Que Puede y que no Puede Hacerse en el Espacio Público

\begin{tabular}{|c|c|c|c|}
\hline & Que puede hacerse & $\begin{array}{c}\text { Que no puede } \\
\text { hacerse }\end{array}$ & $\begin{array}{l}\text { Violaciones en las } \\
\text { que se incurren }\end{array}$ \\
\hline Estudiantes & $\begin{array}{l}\text { Recrearse. Dialogar, } \\
\text { Divertirse. Andar } \\
\text { libremente. Educarse, } \\
\text { Pasear. } \\
\text { Transitar. Acciones } \\
\text { que no escandalicen. } \\
\text { Trabajar. }\end{array}$ & $\begin{array}{l}\text { Crear espacios violentos, } \\
\text { raponar. Impedir el libre } \\
\text { desplazamiento. Usar } \\
\text { drogas, contaminar. } \\
\text { Invadir con ventas } \\
\text { ambulantes. Parquear } \\
\text { automóviles. Hacer } \\
\text { fiestas. }\end{array}$ & $\begin{array}{l}\text { Perdida de la esencia } \\
\text { del espacio como } \\
\text { escenario humano. } \\
\text { Falta de civismo } \\
\text { y de normas de } \\
\text { convivencia. Pérdida } \\
\text { de la estética. } \\
\text { Impedimento del } \\
\text { descanso mental. } \\
\text { Violación al derecho } \\
\text { del peatón. }\end{array}$ \\
\hline $\begin{array}{l}\text { Vendedores } \\
\text { Estaciona- } \\
\text { rios }\end{array}$ & $\begin{array}{l}\text { Transitar. Organizarse } \\
\text { para no obstaculizar } \\
\text { el paso. Cuidar y } \\
\text { mantener limpios los } \\
\text { espacios. Instalar } \\
\text { ventas con permiso. } \\
\text { Trabajar. }\end{array}$ & $\begin{array}{l}\text { Contaminar. Robar. } \\
\text { Ocupar es pacio } \\
\text { i n d e bi d a m e n te. } \\
\text { Detenerse en la vía. } \\
\text { Actos violentes. Ventas } \\
\text { indebidas. Parquear en } \\
\text { andenes. Quitar a los } \\
\text { vendedores de los sitios } \\
\text { públicos. }\end{array}$ & $\begin{array}{l}\text { Ventas que impiden } \\
\text { el libre paso. } \\
\text { Incorrecto se hace } \\
\text { por necesidad. }\end{array}$ \\
\hline $\begin{array}{l}\text { Trabajadores } \\
\text { Formales }\end{array}$ & $\begin{array}{l}\text { Mantenerlos aseados. } \\
\text { Despejar los andenes. } \\
\text { Transitar. Recrearse. } \\
\text { Sentar una voz de } \\
\text { protesta. }\end{array}$ & $\begin{array}{l}\text { Ocuparlos con ventas } \\
\text { estacionarias. Usarlos } \\
\text { c o m o s e r vi cio s } \\
\text { sanitarios. Parquear } \\
\text { vehículos. Cerrar las } \\
\text { calles para fiestas. }\end{array}$ & $\begin{array}{l}\text { No hay autoridad } \\
\text { que haga cumplir } \\
\text { la norma. Violación } \\
\text { del libre tránsito. } \\
\text { Falta de conciencia } \\
\text { ciudadana. Encontra } \\
\text { de los principios } \\
\text { ciudadanos. }\end{array}$ \\
\hline
\end{tabular}

Fuente: Espacio Público en el Distrito Turístico y Cultural de Cartagena de Indias. Reglamentación y Problemáticas Actuales. Gustavo Corrales Villegas. Trabajo de Grado. Facultad de Derecho y Ciencias Políticas. Universidad de Cartagena, 2.000. 
BIOGRAFIA

\section{CARMEN CABRALES VARGAS}

Socióloga Universidad Pontificia Bolivariana. Especialista en Teoría, Métodos y Técnicas de Investigación Social, Universidad de Cartagena-ICFES. Docente hasta el año 2004 de la Facultad de Ciencias Sociales y Educación de la Universidad de Cartagena. Investigadora en el tema de ciudad con publicaciones: La educación ciudadana en la mira del Plan estratégico Cartagena Siglo XXI, 1998. Los barrios populares en Cartagena de Indias, Universidad Jorge Tadeo Lozano-Banco de la República, agosto 2.000. La Radio local cartagenera en la construcción simbólica mediática de la ciudad, revista Palobra, 2003. Miembro del Gruplac reconocido y clasificado por Colciencias en categoría C: Cultura, ciudadanía y poder en contextos locales. E Mail: ccabralesv@yahoo.com

\section{MARCELO CÁCERES CABRALES}

Egresado Programa de Historia, Facultad de Ciencias Humanas, Universidad de Cartagena. Docente del Colegio Mayor de Bolívar. Miembro del grupo de investigación, Virtuales, inscrito en Colciencias. Coinvestigador del macroproyecto: Maqueta Virtual de Centro Histórico de Cartagena de Indias. Publicaciones en: Fortified Places, Recurso de fortificación abaluartada, http://www.fortified-places.com/.E Mail: cacerescabrales@gmail.com 